\title{
The GreenSeeker Handheld: A Research Brief on Farmer Technology Adoption and Disadoption
}

\author{
Daniel Lapidus, Annah Latané, Ivan Ortiz-Monasterio, Robert Beach, \\ and María Elena Cárdenas Castañeda
}

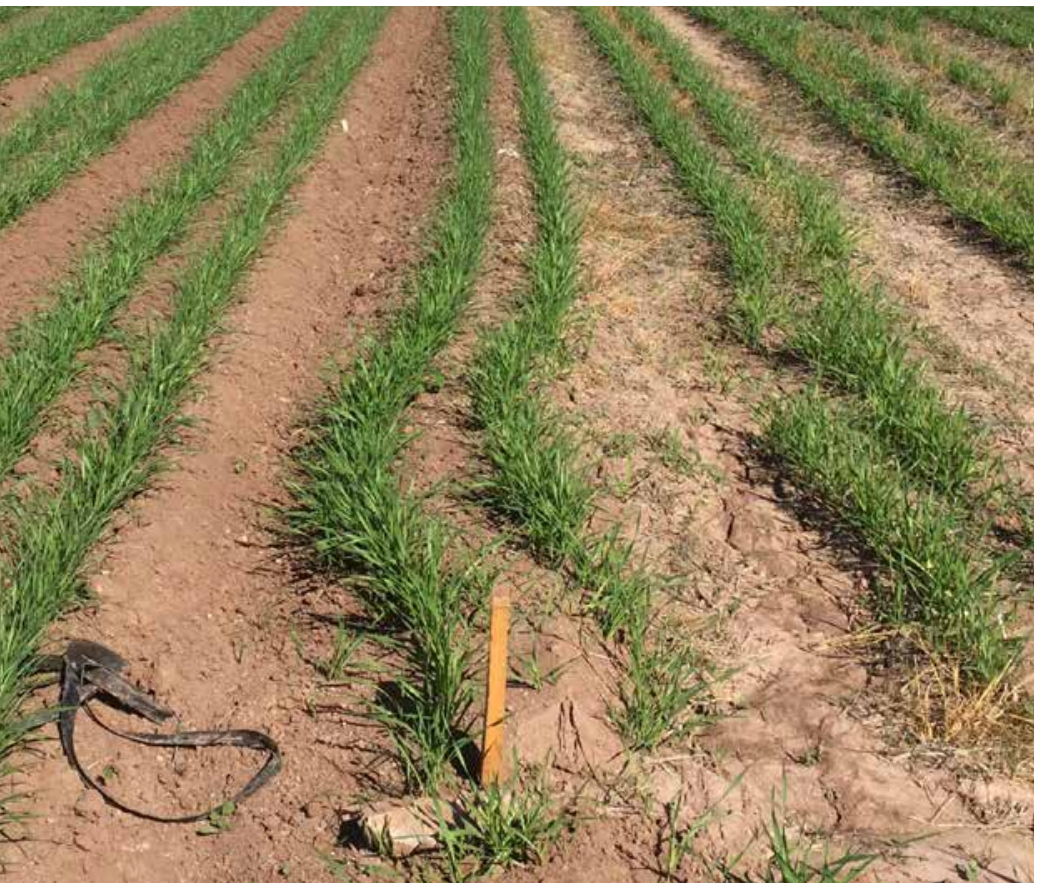

Wheat farmers throughout the Yaqui Valley in Sonora, Mexico, have widely adopted the GreenSeeker Handheld crop sensor to help them apply the right amount of nitrogen fertilizer, reducing their input costs and helping to increase their agricultural profits. Farmers have been using the GreenSeeker Handheld for more than 10 years. In addition to financial benefits, its use has also led to significant environmental benefits in the form of avoided greenhouse gas emissions. Despite additional profits of more than $\$ 37$ USD per hectare and a cumulative reduction of more than 9,500 tonnes $\mathrm{CO}_{2}$ equivalent of avoided greenhouse gas emissions, the number of farmers using this technology has declined sharply in the 2015-2016 growing season. We summarize the state of knowledge around the GreenSeeker Handheld as a promising

\section{Key Findings}

- The GreenSeeker Handheld has increased profits for wheat farmers in the Yaqui Valley, Mexico, and has reduced greenhouse gas emissions significantly.

- The technology was initially adopted by farmers when the research institution (CIMMYT) successfully engaged with the umbrella farmer association (AOASS).

- Now disadoption is occurring, which may be caused by different factors. Further research is needed to better understand the causes.

- A business model may be needed to better align incentives and address farmer needs.

agricultural technology with broad potential for being adopted globally, although higher farmer profits and environmental benefits have not been sufficient to ensure continued adoption. We also provide lessons learned to help inform the sustainable transfer of this promising agricultural technology.

\section{Geography and Technology}

The Yaqui Valley is Mexico's largest wheat-producing region, and it is agro-ecologically similar to $40 \%$ of the developing world's wheat production. 1, 2 Agriculture in the Valley has become mechanized over the last few decades, and nitrogen (N) fertilizer applications have doubled since the mid-1970s. As with other areas where mechanized agriculture has taken root, fertilizer applications represent the largest production cost for farmers, and overapplication represents a significant source of environmental pollution including greenhouse gas emissions, agricultural runoff, and deposition. ${ }^{3}$ 
To address these issues, the International Maize and Wheat Improvement Center (CIMMYT) collaborated with Oklahoma State University to design an in-field, handheld, low-cost $\mathrm{N}$ diagnostic tool that provides site-specific fertilizer recommendations to farmers. The tool diagnoses nutrient needs of the wheat crop midseason, by estimating the yield potential to more accurately assess the nutrient needs of the crop. The precise readings allow farmers to reduce overapplication, thereby reducing fertilizer costs and avoiding air and water pollution. The tool they ultimately developed is called GreenSeeker Handheld (now manufactured by Trimble). ${ }^{*}$

Since the initial pilot phase in 2006, farmers have applied the technology to more than 48,000 cumulative hectares of land throughout the Yaqui Valley (see regional distribution of application over last 3 years in Figure 1). Initial data analysis conducted by RTI and CIMMYT reveals that the tool has led to $\$ 37$ in additional farmer profits per hectare, totaling $\$ 1.8 \mathrm{M}$ of additional profits over an 8-year time period (see Table 1). ${ }^{\dagger}$ The tool has also reduced greenhouse gas emissions by an estimated 9,600 tonnes $\mathrm{CO}_{2} \mathrm{e}$, or the equivalent of taking more than 2,000 cars off the road for a year.‡ Project developers have

* See http://www.trimble.com/Agriculture/gs-handheld.aspx. There are two different versions of the tool.

$\dagger$ These are the results of a recent thorough, independent analysis conducted by RTI International. Analysis compared per hectare farmer revenues (wheat price $\times$ yield) and costs (fertilizer price $\times$ application rate) from individual on-farm test strips with per hectare farmer revenues and costs from comparison areas where the sensor was applied on the same farm (e.g., sensor areas). These are farm level revenues and costs and thus do not include the costs of the technology nor the GreenSeeker technician's time. Used Global Warming Potential of 310 for $\mathrm{N}_{2} \mathrm{O}$.

\$ Greenhouse gas equivalency for passenger vehicles per year was assumed to be 4.7 tonnes C02e/vehicle/year. ${ }^{5}$

\section{Figure 1. Farmer adoption of GreenSeeker Handheld in the Yaqui Valley, from 2011 to 2014.}

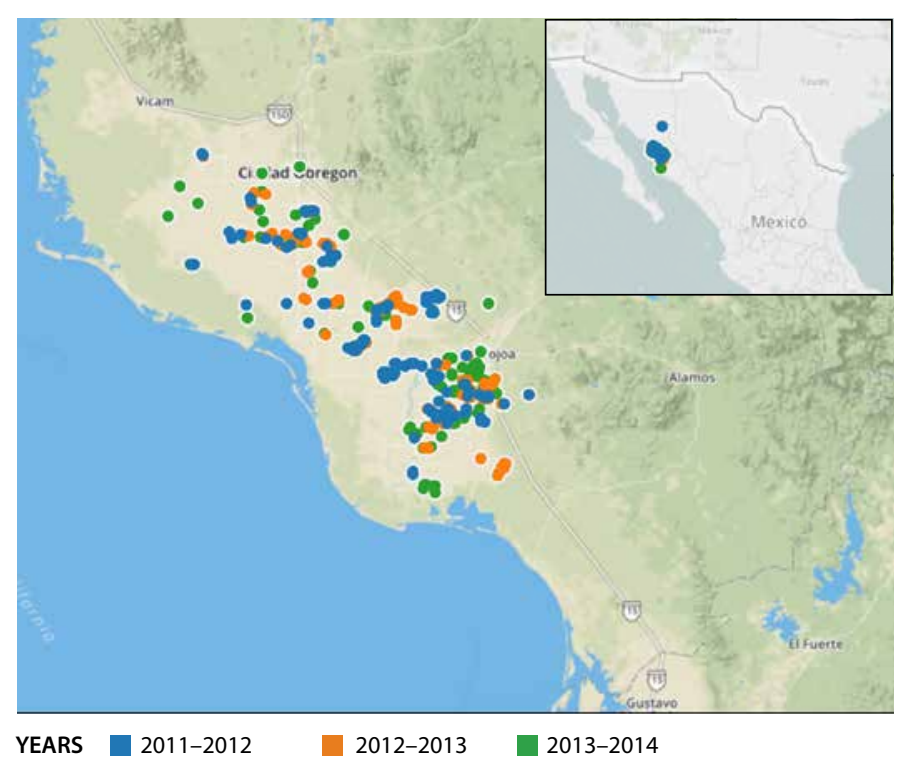

Note: Data provided by the International Maize and Wheat Improvement Center (CIMMYT). Georeferenced in Tableau.

even expanded the technology to other locations in Mexico (Baja California, Guanajuato, Sinaloa) and globally (Pakistan, India, China). GreenSeeker Handheld holds particular promise for improving profits and mitigating emissions in areas where fertilizer is likely to be overapplied. So why did adoption in the Yaqui Valley decline in 2015-2016 rather than expand?

\section{Table 1. GreenSeeker handheld initial results: additional profits and avoided greenhouse gas emissions, by year}

\begin{tabular}{|c|c|c|c|c|c|}
\hline Year & $\begin{array}{c}\text { Additional profits } \\
\text { (USD/ha) }\end{array}$ & $\begin{array}{l}\text { Avoided emissions } \\
\left.\text { (tCO } \mathrm{tC}_{2} \mathrm{e} / \mathrm{ha}\right)\end{array}$ & $\begin{array}{c}\text { Total area } \\
\text { (ha) }\end{array}$ & $\begin{array}{l}\text { Total profits } \\
\text { (USD) }\end{array}$ & $\begin{array}{c}\text { Total avoided } \\
\text { emissions }\left(\mathrm{tCO}_{2} \mathrm{e}\right)\end{array}$ \\
\hline 2006-2007 & $\$ 6.69$ & 0.19 & 2,445 & $\$ 16,352$ & 464 \\
\hline 2008-2009 & $\$ 99.39$ & 0.23 & 6,662 & $\$ 662,182$ & 1,557 \\
\hline 2009-2010 & $\$ 60.42$ & 0.23 & 7,724 & $\$ 466,669$ & 1,752 \\
\hline $2012-2013$ & $\$ 18.66$ & 0.22 & 5,665 & $\$ 105,713$ & 1,264 \\
\hline $2013-2014$ & $\$ 10.56$ & 0.16 & 7,149 & $\$ 75,476$ & 1,163 \\
\hline Total & $\$ 37.39$ & 0.20 & 48,425 & $\$ 1,810,623$ & 9,646 \\
\hline
\end{tabular}

ha $=$ hectare; $\mathrm{tCO}_{2} \mathrm{e}=$ tonnes of carbon dioxide emissions.

Note: Based on 971 observations. Values are in US 2014 dollars. Emissions were calculated using a $\mathrm{N}_{2} 0 \mathrm{Global} \mathrm{Warming} \mathrm{Potential} \mathrm{of} 310$. Results are from an initial analysis of CIMMYT data conducted by RTI International. More complete manuscript is under development. 


\section{Role of Local Institutions in GreenSeeker Handheld Technology Adoption}

There is a long history of agronomic research within the Yaqui Valley, spearheaded by CIMMYT since the 1960s and its predecessor organization the Office of Special Studies since the mid-1940s. CIMMYT collaborated with Stanford University on a series of agricultural projects and research studies in the Yaqui Valley from 1993 to 2008 and comprehensively documented this work in the book Seeds of Sustainability: Lessons from the Birthplace of the Green Revolution in Agriculture. ${ }^{3}$

One instrumental finding of this research was that farmer credit unions influence the amount of inputs (including fertilizer) that farmers apply on their land. The credit unions provide loans to farmers, sell them fertilizer, and link them to outside markets. The loans provided by the credit unions are linked to specific fertilizer recommendations, and any change in management practices that involves "risky" or lower fertilizer applications needs farmer credit union buy-in and approval. The GreenSeeker Handheld involves recommendations to farmers to change their fertilizer use and apply less fertilizer. Because the credit unions even sell fertilizer to farmers, they have a disincentive to approve changes that result in less fertilizer being applied.

To overcome this barrier, CIMMYT worked closely with the farmer credit unions to garner their support. They did this by showing the credit unions how the technology worked and securing enough resources to purchase the devices, train credit union technicians to use the technology, and provide ongoing technical support. The credit unions then not only supported the technology-they supplied the technicians that took the readings on farmer fields and made recommendations to farmers on how much fertilizer to apply. These technicians received a bonus of 120 pesos per hectare of sensor technology transferred. There were several funding sources for this bonus over the years: Fundación Produce Sonora, Association of Agriculture Organizations of Southern Sonora (AOASS), Financiera Rural, MasAgro, and Mexico's Ministry of Agriculture (SAGARPA).

\section{Looking Forward: Analyzing Data and Mobilizing Institutions}

Despite this continued involvement, the success of the technology has still had at least two main impediments to sustained adoption: (1) reliance on outside funding (rather than farmer profit-sharing) to train, equip, and support the farmer advisor's time using the technology (donor fatigue); and (2) long-term political buy-in from farmer union leadership. Both of these issues came to a head during the 2015-2016 growing season. The umbrella organization for the farmer credit unions, AOASS, had a change in leadership prior to the 2015-2016 growing season, coinciding with the worst climatic conditions in more than 35 years, resulting in extremely low yields. Funding to support continued GreenSeeker Handheld diagnostics by farmer advisors began to decrease.

Another factor affecting farmer adoption could be related to farmer perceptions of the technology and what factors they consider important in determining how much nitrogen fertilizer to apply. Although there has been extensive field testing of the technology and data collection on farmer application, there has not been any concerted effort to understand farmers' perceptions of the technology and whether it meets their needs. Despite the sustained farmer profits and the environmental benefits, these factors may have contributed to the farmer credit unions withdrawing their support prior to the 2015-2016 growing season.

As a forward-looking agricultural research institution, CIMMYT has been working with farmer credit unions to collect extensive data on farmer use of the GreenSeeker Handheld to promote fertilizer use efficiency in the Yaqui Valley. The data CIMMYT has collected include historical fertilizer recommendations, actual amount of fertilizer farmers applied, total area where the technology was used, and wheat yields per hectare, as well as which farmer credit union supported the adoption of GreenSeeker on individual producers' farms.

RTI International has been working with CIMMYT to analyze these data to compare the results of using GreenSeeker (baseline) to not using it (counterfactual). Table 1 summarizes the initial results from this analysis, but the analysis also includes information such as yields for different wheat varieties, fertilizer costs, and recommended fertilizer application rates versus actual fertilizer application rates for nearly 1,000 farmers surveyed over an 8-year time frame. The results show sufficient profits and reduced greenhouse gas emissions, but they are missing key qualitative data on farmer perceptions.

This leads to at least two potential strategies for sustainability:

1. The development of a business model or plan that will be more sustainable than relying on outside funding. Such a plan should be based on a better understanding of farmers' needs and perceptions of the technology. The business model or plan could involve a financial arrangement between the farmers and the credit unions, or perhaps a different arrangement that better meets farmer needs. 


\section{The GreenSeeker Handheld}

2. CIMMYT has been leading the collection of data on greenhouse gas emissions from fertilizer applications, and thus has data that allow for the calculation of greenhouse gas emissions that can be mitigated by using the GreenSeeker Handheld. These data are a prerequisite for voluntary carbon markets that could be an avenue for additional source of revenue in the future. Pursuing this strategy could also help Mexico meet its national carbon reduction goals of reducing emissions by $22 \%$ by 2030.6

\section{Conclusion}

This research brief highlights the importance of engaging with decision makers and collecting good data to inform sustainable agricultural technology adoption. The GreenSeeker Handheld has provided increased profits to Yaqui Valley farmers and environmental benefits in terms of reduced greenhouse gas emissions, but that has not been enough to ensure adoption. Government policies as well as cost-sharing arrangements or environmental markets may also be necessary to ensure that adoption, but further research on famer perceptions is also critical. CIMMYT has collected excellent data on adoption thus far, but stakeholders and policymakers must use that data effectively to inform strategies to ensure future sustainability.

\section{References}

1. Fischer RA, Byerlee D, Edmeades GO. Crop yields and global food security: will yield increase continue to feed the world? In: ACIAR Monograph No. 158. Canberra, Australia: Australian Centre for International Agricultural Research; 2014.

2. Pingali PL, Rajaram S. Global wheat research in a changing world: options and sustaining growth in wheat productivity. In: CIMMYT 1998-1999 world wheat facts and trends: global wheat research in a changing world: challenges and achievements. Mexico, D.F., Mexico: CIMMYT; 1999.

3. Matson PA, Naylor R, Ortiz-Monasterio I. Looking for win-wins in intensive agriculture. In: Matson PA, editor. Seeds of sustainability: lessons from the birthplace of the green revolution in agriculture. Washington, DC: Island Press; 2012. p. 31-46.

4. Ortiz-Monasterio I, Raun W. Reduced nitrogen and improved farm income for irrigated spring wheat in the Yaqui Valley, Mexico, using sensor based nitrogen management. J Agricultural Sci. 2007;145(3):215-222.

5. US Environmental Protection Agency. GHG equivalencies calculatorcalculations and references. 2016 May 31 [cited 2016 September 24].; Available from: https://www.epa.gov/energy/ghg-equivalencies-calculatorcalculations-and-references

6. México Gobierno de la República. Intended nationally determined contribution. 2015 [cited 2016 September 24]. Available from: http:// www4.unfccc.int/submissions/INDC/Published\%20Documents/Mexico/1/ MEXICO\%20INDC\%2003.30.2015.pdf

\begin{abstract}
About the Authors
Daniel Lapidus, MA, is a senior economist and policy analyst in RTI's Environmental, Technology and Energy Economics group.

Annah Latané, MS, is a food and agriculture specialist in RTI's International Development Group.

Ivan Ortiz-Monasterio, PhD, is a principal scientist with the Sustainable Intensification Program at the International Maize and Wheat Improvement Center (CIMMYT), Obregon, Sonora State, Mexico.
\end{abstract}

Robert Beach, PhD, is a senior economist and RTI Fellow in RTI's Environmental Engineering and Economics Division.

María Elena Cárdenas Castañeda, MS, is a research associate with CIMMYT's Sustainable Intensification Program.

\section{Acknowledgments}

For supporting the greenhouse gas emission reduction measurements that informed this research brief, we acknowledge the CGIAR Fund Council, Australia (ACIAR), Irish Aid, European Union, International Fund for Agricultural Development (IFAD), Netherlands, New Zealand, Switzerland, UK, USAID, and Thailand for funding to the CGIAR Research Program on Climate Change, Agriculture and Food Security (CCAFS).

RTI Press Research Briefs and Policy Briefs are scholarly essays on policy, methods, or other topics relevant to RTI areas of research or technical focus.

RTI International, 3040 East Cornwallis Road, PO Box 12194 Research Triangle Park, NC 27709-2194 USA
919.541 .6000
rtipress@rti.org
www.rti.org

(O2017 RTI International. All rights reserved. Credit must be provided to the author and source of the publication when the content is quoted. No part of this publication may be reproduced in any form by any electronic or mechanical means without permission in writing from the publisher. RTI International is a registered trademark and a trade name of Research Triangle Institute.

RTI Press publication RB-0014-1705 www.rti.org/rtipress 